\title{
Dietary fiber showed no preventive effect against colon and rectal cancers in Japanese with low fat intake: an analysis from the results of nutrition surveys from 23 Japanese prefectures Shigeyuki Nakaji *1, Tadashi Shimoyama ${ }^{1}$, Takashi Umeda ${ }^{1}$, Juichi Sakamoto ${ }^{2}$, Shuji Katsura ${ }^{1}$, Kazuo Sugawara ${ }^{1}$ and David Baxter 3
}

Address: ${ }^{1}$ Department of Hygiene, Hirosaki University School of Medicine Zaifu-cho 5, Hirosaki, o36-8562 Japan, ${ }^{2}$ First Department of Internal Medicine, Hirosaki University School of Medicine, Hirosaki, o36-8562 Japan and 3Research Graduate School, Faculty of Social and Health Sciences and Education, The University of Ulster, Shore Road, Newtownabbey, County Antrim, BT37 OQB, Northern Ireland, UK

E-mail: Shigeyuki Nakaji* nakaji@srhajamaica.com; Tadashi Shimoyama -nakaji@cc.hirosaki-u.ac.jr;

Takashi Umeda - TUME@cc.hirosaki-u.ac.jp; Juichi Sakamoto - nakaji@srhajamaica.com; Shuji Katsura - nakaji@srhajamaica.com; Kazuo Sugawara-KSAGA@cc.hirosaki-u.ac.jp; David Baxter - nakaji@srhajamaica.com

*Corresponding author

Published: 29 October 2001

BMC Cancer 200I, I:14

This article is available from: http://www.biomedcentral.com//47/-2407/I//4

(C) 200 I Nakaji et al; licensee BioMed Central Ltd. Verbatim copying and redistribution of this article are permitted in any medium for any non-commercial purpose, provided this notice is preserved along with the article's original URL. For commercial use, contact info@biomedcentral.com
Received: 8 May 2001

Accepted: 29 October 2001

\begin{abstract}
Background: Since Fuchs' report in 1999, the reported protective effect of dietary fiber from colorectal carcinogenesis has led many researchers to question its real benefit. The aim of this study is to evaluate the association between diet, especially dietary fiber and fat and colorectal cancer in Japan.
\end{abstract}

Methods: A multiple regression analysis (using the stepwise variable selection method) was performed using the standardized mortality ratios (SMRs) of colon and rectal cancer in 23 Japanese prefectures as objective variables and dietary fiber, nutrients and food groups as explanatory variables.

Results: As for colon cancer, the standardized partial correlation coefficients were positively significant for fat $(I, I 3, P=0.000)$, seaweeds $(0.4 I, P=0.026)$ and beans $(0.45, P=0.017)$ and were negatively significant for vitamin $A(-0.63, P=0.003)$, vitamin $C(-0.42, P=0.019)$ and yellow-green vegetables $(-0.37, P=0.046)$. For rectal cancer, the standardized partial correlation coefficient in fat $(0.60, P=0.002)$ was positively significant. Dietary fiber was not found to have a significant relationship with either colon or rectal cancers.

Conclusions: This study failed to show any protective effect of dietary fiber in subjects with a low fat intake (Japanese) in this analysis, which supports Fuchs' findings in subjects with a high fat intake (US Americans).

\section{Introduction}

It is currently believed that dietary fiber and dietary fat are the most significantly associated dietary factors in colorectal carcinogenesis [1-3]. Current epidemiological evidence would suggest that dietary fat is a more significant risk factor for colorectal cancer than the evidence indicating dietary fiber to be a preventative factor [1-4]. Furthermore, since Fuchs' report [5] in 1999, the reported protective effect of dietary fiber on colorectal carcinogenesis has led many researchers to question its real benefit. However, care should be taken in ascertaining the effect of dietary factors in carcinogenesis, including 
colorectal carcinogenesis, as the protective effects of dietary factors on carcinogenesis may not only be based upon the balance of the overall diet, but also on the interaction of specific dietary components, such as dietary fiber, nutrients and other foods. Furthermore, Fuchs' results generated many points of controversy against the study, such as the inaccuracy of the dietary survey (using a food-frequency questionnaire); the basic values for fiber may not merit such analysis (the data on fiber are drawn from a 1976 article by Southgate et al., which gives fiber values for a limited number of foods in the United Kingdom); and the possible effect of fiber consumed early in life on the risk of colorectal cancer cannot be ruled out; no assessment of colonic function was taken into consideratioon (so the Fuchs' article leaves unchallenged the evidence that bulkier stools and faster transit through the gut reduce the risk of colorectal cancer) [6] and so on. It is thus logical to attempt to extend Fuchs' cohort study to include Japanese subjects, whose intake of fat is lower than the US subjects, and to see if the study arrives at the same conclusions. Furthermore, care should be taken in estimating the result of intervention studies $[7,8]$, and further studies are thus required in other national groups.

As a nation, Japan is unique in that accurate regional dietary data are available, because many prefectures have periodically performed dietary surveys using similar methods. Japan is therefore an appropriate model to analyze geographically the relationship between dietary habit and colorectal cancer.

To evaluate the association between diet and colorectal cancer, we examined the correlation between dietary intake around 1990 and the standardized mortality ratios (SMRs) of colon and rectal cancer between 1995 and 1997 in 23 Japanese prefectures.

\section{Materials and Methods}

\section{Intake of dietary fiber and nutrients}

We collected reports on the intake of food groups and nutrients (using the weighing method) in 23 prefectures, representing 50\% of all 47 prefectures in Japan (Figure 1). These surveys were performed in 1987 and 1991. The number of survey subjects and the population in each prefecture in 1995 varied from 162 to 3,057 (Table 1), and from 816,008 to $11,734,920$, respectively. There were small differences in the mean ages (46.3 - 54.1 years old) and the male to female ratios (0.78-1.0o) among the 23 selected prefectures.

The dietary survey was performed as follows. A staff dietarian demonstrated the survey methods and procedures to the housewife or whoever usually cooked in the family. The responsible person in each household weighed and recorded the cooked dishes and the ingredients for each dish, the amount consumed and any left uneaten, and the approximate proportions by which the family members shared each dish or food. The type and amount of foods eaten outside the home were also recorded as meals taken by each individual.

Nutrients included fat, carbohydrate, protein, vitamins $\left(\mathrm{A}, \mathrm{B}_{1} . \mathrm{B}_{2}\right.$ and $\left.\mathrm{C}\right)$, and mineral intake (iron); food included 20 major food groups (rice, barley, wheat, seeds, potatoes, confectionaries, beans, fruits, yellow-green vegetables, other vegetables, pickles, mushrooms, seaweeds, meat, egg, oil, milk, fish, juice and alcoholic drink in addition to other foods). The daily dietary fiber intake per capita was calculated from the food intake from each individual nutrition survey by substituting the dietary fiber content in each food (measurement value), obtained by the modified Prosky AOAC method [9] and the modified Southgate method [10]. We calculated the different components under each method: the water-soluble and insoluble fibers from the modified Prosky AOAC method, and cellulose, hemicellulose and lignin from the modified Southgate method.

\section{Calculation of SMR of colon and rectal cancer}

We used data from the National Vital Statistics [11] to record the number of deaths from colon cancer or rectal cancer between 1995 and 1997 in the 23 target prefectures. The SMRs from colon and rectal cancer, over the same period, by age group in all of Japan were also obtained from the Vital Statistics [12]. The population by age group of each prefecture was obtained from the Japanese Census Report [12]. The SMRs were calculated as an average for the three years.

\section{Statistical analysis}

A multiple regression analysis (based on the stepwise variable selection method) was carried out using the Statistical Package for the Social Sciences (SPSS), with the SMRs of colon cancer and rectal cancer as objective variables, and dietary fiber, nutrients and food groups as explanatory variables. A probability value $(\mathrm{P})$ of less than $0.05(P<0.05)$ was considered to be significant.

\section{Results \\ SMRs of colon and rectal cancers and dietary intake}

In general, intakes of dietary fiber and nutrients were slightly higher in northeastern Japan than in southwestern Japan (Table 2) and the SMRs of colon and rectal cancers were also slightly higher in northeastern than in southwestern Japan (Table 1).

\section{Result of multiple regression analysis}

As for colon cancer, the standardized partial correlation coefficients were positively significant for fat $(1.13, \mathrm{P}=$ 


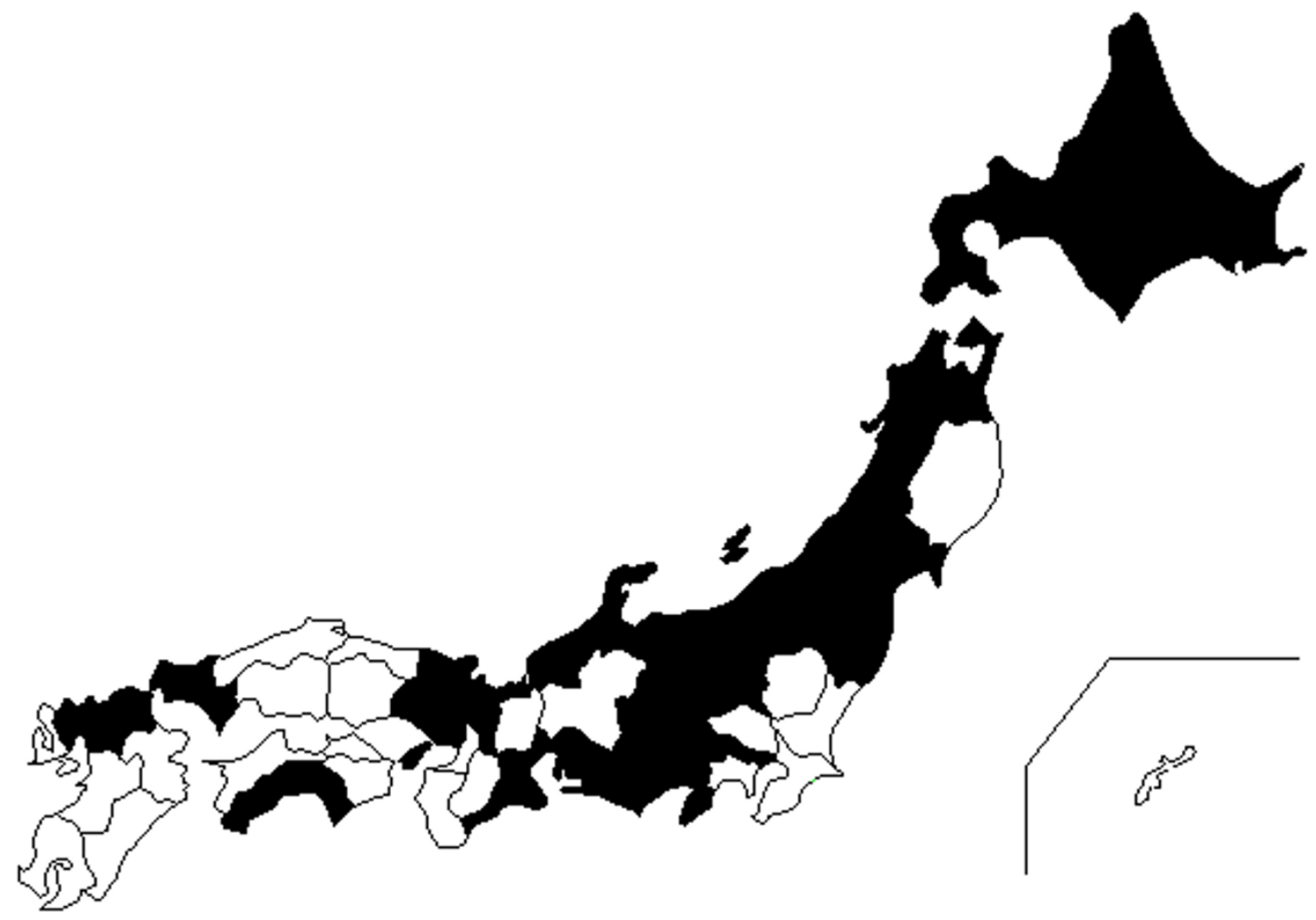

Figure I

Location of the 23 prefectures selected. Target prefectures are shown in black.

0.000), seaweeds (0.41, $\mathrm{P}=0.026)$ and beans $(0.45, \mathrm{P}=$ $0.017)$ and were negatively significant for vitamin A ($0.63, \mathrm{P}=0.003)$, vitamin $\mathrm{C}(-0.42, \mathrm{P}=0.019)$ and yellow-green vegetables $(-0.37, \mathrm{P}=0.046)$ (Table 3$)$. For rectal cancer, the standardized partial correlation coefficient in fat (0.60, $\mathrm{P}=0.002)$ was positively significant. Dietary fiber was not seen to have a significant relationship with either colon or rectal cancers.

\section{Discussion}

Assuming that diet is a factor involved in the development of colon and rectal cancers, any dietary-related effect would be expected to become apparent after a certain latent period, the duration of which is however unknown. Furthermore, the period between the development of colon and rectal cancers and death due to these disease is also unknown. For this study, the authors essentially defined the period in which dietary intake is able to have an influence on death from colon cancer as approximately 10 years. This is a limitation of this study, because it is clear that 10 years is too short. Furthermore, there were differences in the survey year among the 23 prefectures examined up to a maximum of 4 years. This is also a potential limitation.
From the previous case-control and cohort studies in Japan concerning fiber source foods and their preventive effect on colon and rectal cancer, three reports showed significant preventive effects in vegetables and fruits from a total of nine reports, and two out of five reports on rice showed a preventive effect. As for beans or seaweeds, one and two reports from respective totals of five and three showed significant preventive effects [13]. Only two reports from Ohta and colleagues examined the relationship of pure dietary fiber on colorectal cancer or colon polyps. The authors reported that dietary fiber intakes in patients with colorectal cancer and colon polyp were higher than those in controls $[10,14]$. On the other hand, one report from a total of five on dietary fat showed a promoting effect. As mentioned above, there are not many studies which show significant relationships between the effects of either dietary fiber or fat on colorectal cancer in Japan.

In this study, it was shown that there were significant relationships between fat intake and colon and rectal cancers, but no relationship between dietary fiber intake and colon or rectal cancers, thus demonstrating that the promoting effect of dietary fat was greater than the protec- 
Table I: Number of subjects and SMR' of colon cancer and rectal cancer in 23 Prefectures, from northeastern to southwestern in order.

\begin{tabular}{|c|c|c|c|c|}
\hline Prefecture & $\begin{array}{c}\text { No. of } \\
\text { Subjects }\end{array}$ & Survey year & Col SMR & Rec SMR \\
\hline Hokkaido & 950 & 1989 & 108.0 & 104.9 \\
\hline Aomori & $163 \mid$ & $199 \mid$ & 118.9 & 119.7 \\
\hline Miyagi & 162 & 1989 & 89.8 & 109.8 \\
\hline Akita & 1254 & 1987 & 118.1 & 107.8 \\
\hline Yamagata & 1698 & 1990 & 113.0 & 97.9 \\
\hline Fukushima & 632 & 1990 & 96.4 & 107.0 \\
\hline Gunma & 928 & 1990 & 88.9 & 87.2 \\
\hline Tokyo & 1319 & 1991 & 116.1 & 109.9 \\
\hline Toyama & 957 & 1990 & 101.4 & 84.9 \\
\hline Nagano & 3057 & 1989 & 91.8 & 88.4 \\
\hline Yamanashi & 1642 & 1989 & 72.8 & 100.2 \\
\hline Niigata & 2290 & 1989 & 97.7 & 109.3 \\
\hline Fukui & 212 & 1987 & 78.4 & 70.0 \\
\hline Ishikawa & 849 & 1987 & 102. & 79.8 \\
\hline Shizuoka & 1367 & 1989 & 82.7 & 97.8 \\
\hline Aichi & 484 & 1991 & 104.9 & 103.9 \\
\hline Mie & 700 & 1988 & 81.6 & 89.1 \\
\hline Kyoto & 1523 & 1987 & 107.8 & 95.2 \\
\hline Hyogo & 500 & 1988 & 103.8 & 97.8 \\
\hline Yamaguchi & 1579 & 1990 & 93.8 & 100.5 \\
\hline Kochi & 1211 & 1990 & 78.0 & 106.2 \\
\hline Fukuoka & 1532 & 1989 & 108.4 & 98.0 \\
\hline Saga & 1624 & 1989 & 92.3 & 93.3 \\
\hline
\end{tabular}

I: Standardized mortality rate Col SMR: Colon cancer SMR; Rec SMR: Rectal cancer SMR

Table 2: Daily intake of dietary fiber, energy, protein, fat and carbohydrate in 23 prefectures, From northeastern to southwestern in order.

\begin{tabular}{|c|c|c|c|c|c|c|}
\hline \multirow{2}{*}{ Prefecture } & \multicolumn{2}{|c|}{ Dietary Fiber $(\mathrm{g})$} & \multirow{2}{*}{$\begin{array}{l}\text { Energy } \\
\text { (kcal) }\end{array}$} & \multirow{2}{*}{$\begin{array}{l}\text { Protein } \\
\text { (g) }\end{array}$} & \multirow{2}{*}{$\begin{array}{l}\text { Fat } \\
\text { (g) }\end{array}$} & \multirow{2}{*}{$\begin{array}{c}\text { Carbohydrate } \\
\text { (g) }\end{array}$} \\
\hline & Prosky & Southgate & & & & \\
\hline Hokkaido & 16.1 & 17.2 & 2106 & 82.6 & 57.0 & 305 \\
\hline Aomori & 17.6 & 18.8 & 2174 & 88.4 & 56.0 & 315 \\
\hline Akita & 17.1 & 17.7 & 2012 & 83.4 & 57.0 & 282 \\
\hline Yamagata & 15.7 & 16.5 & 2088 & 80.6 & 56.1 & 299 \\
\hline Miyagi & 16.6 & 17.8 & 2117 & 82.7 & 55.9 & 308 \\
\hline Fukushima & 15.8 & 16.9 & 2079 & 80.0 & 56.0 & 301 \\
\hline Gunma & 19.3 & 20.5 & 2289 & 89.8 & 58.9 & 334 \\
\hline Tokyo & 14.5 & 15.5 & 1985 & 77.9 & 57.9 & 271 \\
\hline Toyama & 15.9 & 17.0 & 2044 & 78.8 & 55.6 & 283 \\
\hline Nagano & 18.6 & 18.6 & 2135 & 80.2 & 49.0 & 302 \\
\hline Yamanashi & 16.4 & 17.1 & 1986 & 81.4 & 51.5 & 286 \\
\hline Niigata & 16.1 & 17.0 & 2068 & 77.5 & 55.4 & 296 \\
\hline Fukui & 13.2 & 15.1 & 2061 & 77.4 & 46.3 & 316 \\
\hline Ishikawa & 13.1 & 14.6 & 2063 & 76.0 & 51.0 & 325 \\
\hline
\end{tabular}


Table 2: Daily intake of dietary fiber, energy, protein, fat and carbohydrate in 23 prefectures, From northeastern to southwestern in order. (Continued)

\begin{tabular}{lllllll}
\hline Shizuoka & 14.8 & 15.4 & 1987 & 80.1 & 53.6 & 296 \\
Aichi & 14.9 & 16.0 & 2057 & 81.3 & 54.9 & 293 \\
Mie & 15.2 & 16.3 & 2073 & 81.8 & 83.2 & 299 \\
Kyoto & 15.0 & 16.3 & 2146 & 80.5 & 55.0 & 324 \\
Hyogo & 12.4 & 14.4 & 2083 & 81.6 & 54.0 & 295 \\
Yamaguchi & 15.5 & 16.2 & 2081 & 81.3 & 55.0 & 291 \\
Kochi & 13.6 & 14.3 & 1928 & 80.3 & 54.0 & 278 \\
Fukuoka & 14.9 & 16.0 & 2063 & 81.7 & 56.4 & 297 \\
Saga & 14.3 & 15.3 & 2070 & 77.8 & 56.3 & 295
\end{tabular}

Table 3: Results of multiple regression analysis.

\begin{tabular}{lll}
\hline Explanatory variable & $\begin{array}{l}\text { Standardized } \\
\text { partial corre- } \\
\text { lation coeffi- } \\
\text { cient }\end{array}$ & \\
\hline
\end{tabular}

\begin{tabular}{lccc} 
Colon & & & \\
Nutrients & & & \\
Fat & 1.13 & 0.000 & \\
Vitamin A & -0.63 & 0.003 & 0.61 \\
Vitamin C & -0.42 & 0.019 & \\
Food groups & & & \\
Seaweeds & 0.41 & 0.026 & \\
YG vegetables & -0.37 & 0.046 & 0.47 \\
Beans & 0.45 & 0.017 & \\
Rectum & & & \\
Nutrients & & & \\
Fat & 0.60 & 0.002 & 0.36 \\
& & & \\
\hline
\end{tabular}

I: yellow-green vegetables

tive effect of dietary fiber. Furthermore, seaweeds and beans also demonstrated a carcinogenic promoting relationship with colon cancer even though these are well known as a source of dietary fiber. Hence, our data failed to show any protective effect of dietary fiber on colorectal carcinogenesis in subjects in the low fat intake group (Japanese; $25 \%$ in $1977-1978$ and 29\% in 1994-1995 in men and women, respectively) [15] in this analysis, while Fuchs showed the same result in subjects in the high fat intake group (US subjects; 42\% and 40\% in 1977-1978 and $34 \%$ and $32 \%$ in $1994-1995$ in men and women, respectively) [16]. However, we could not divide the total fat intake into animal fat and plant fat, so that it is unclear which type of fat has more influence on these cancers.

On the other hand, vitamin A (including carotenes) $[17,18]$ and vitamin $C[19,20]$ are believed to offer bene- ficial dietary factors against colorectal cancer through their anti-oxidative action, though the preventive effects of these dietary factors have not been reported in Japan. In this study, we also obtained similar results, even though the correlation coefficients were lower than those of fat.

The current results revealed that the number of nutrients and food groups that were significantly related with colon cancer was greater than those related to rectal cancer. This would suggest that colon cancer is affected by environmental factors, including the dietary factor, more than rectal cancer.

\section{Competing interests \\ None declared}

\section{Acknowledgements}

The authors would like to thank to Drs. Iwane and Ohta, First Department of Internal Medicine, Hirosaki University School of Medicine for their suggestions in writing this manuscript.

\section{References}

I. Nakaji S, Sugawara K, Ohta M, Iwane S, Ishiguro S, Tamura K: An epidemiological study on relationship between colorectal cancer and dietary fiber intake in Japan. $P$ Phys Fit Nutr Immunol 1997, 7:72-89

2. Lipkin M, Reddy B, Newmark H, Lamprecht SA: Dietary factors in human colorectal cancer. Ann Rev Nutr 1999, 19:545-586

3. Levin B: Nutrition and colorectal cancer. Cancer 1992, 70:17231726

4. Boutron MC, Wilpart M, Faivre P: Diet and colorectal cancer. Eur $P$ Cancer Prev 1991, Suppl 2:13-20

5. Fuchs CS, Giovannucci EL, Colditz GA, Hunter DJ, Stampfer MJ, Rosner B, Speizer FE, Willett WC: Dietary fiber and the risk of colorectal cancer and adenoma in women. N Eng $P$ Med 1999, 340:169-176

6. Ravin ND, Mohandas KM, Cummings JH, Heaton KW, Jewis SJ, Madar Z, Stark A, Camire ME, Fuchs CS, Willett WC: Dietary fiber and colorectal cancer. N Eng P Med 1999, 340:1924-1926

7. Schatzkin A, Lanza E, Corle D, Lance P, Iber F, Caan B, Weissfeld M, Burt R, Cooper MR, Kikendall JW, Cahill P: Lack of effect of a lowfat, high-fiber diet on the recurrence of colorectal adenomas. Polyp Prevention Trial Study Group. N Eng P Med 2000, 342:1149-1155

8. Alberts DS, Martinez ME, Roe DJ, Guillen-Rodriguez JM, Marshall JR, van Leeuwen JB, Reid ME, Ritenbaugh C, Vargas PA, Bhattacharyya $A B$, Earnest DL, Sampliner RE: Lack of effect of a high-fiber cereal supplement on the recurrence of colorectal adenomas. 
Phoenix Colon Cancer Prevention Physicians' Network. N Engl J Med 2000, 342: I I56-I I 62

9. Resources Council, Science and Technology Agency. Standard Tables of Food Composition in Japan-Dietary Fiber-, 1992

10. Ohta M, Ishiguro S, Iwane S, Nakaji S, Tsuchida S, Aisawa T, Yoshida $Y$ : An epidemiological study on relationship between intake of dietary fiber and colonic diseases. Jpn P Gastroenterol 1985, 82:5I-57

II. Vital Statistics of Japan 1991, Statistics and Information Department, Minister's Secretariat, Ministry of Health and Welfare, Tokyo, 1994

12. Bureau of Statistics, Office of the Prime Minister. Bureau, Ministry of Finance. Population of Japan in 1995, Tokyo, 1998

13. The committee of cancer prevention of the Japanese Society of Cancer Epidemiology. The relationship between life habit and cancers of main sites. Kyushu University Printing, Fukuoka, 1998

14. Ohta M: An epidemiological study on relationship between intake of dietary fiber and colorectal cancer. J Jpn Soc Colo-proct 1987, 40:741-746

15. Section of Nutrition, Bureau of Public Health, Ministry of Health and Welfare. National Nutrition Survey. Tokyo Daiichi Publishing Co., Tokyo, 1948-1999

16. Enns CW, Goldman JD, Cook A: Trends in Food and Nutrient Intakes by Adults: NFCS 1977-78, CSFII 1989-9I, and CSFII 1994-95. Family Eco Nutr Rev 1997, 10(4): $12-20$

17. Ziegler RG, Subar AF, Craft NE, Ursin G, Patterson BI, Graubard BI: Dose $\beta$-carotene explain why reduced cancer risk is associated with vegetables and fruit intake? Cancer Res 1992, 52(Supple):2060s-2066s

18. La Vecchia C, Ferraroni M, Mezzetti M: Attributable risks for colorectal cancer in northern Italy. Int P Cancer 1996, 66:60-64

19. Almendingen K, Trygg K, Larsen S: Dietary factors and colorectal polyps: A case-control study. Eur J Cancer Prev 1995, 4:239-246

20. Calacchio T, Memoli V, Hildebrandt L: Antioxidant vs carotenoids: Inhibitors or promoters of experimental colorectal cancers. Arch Surg 1989, 124:217-221

Publish with BioMed Central and every scientist can read your work free of charge

"BioMedcentral will be the most significant development for disseminating the results of biomedical research in our lifetime."

Paul Nurse, Director-General, Imperial Cancer Research Fund

Publish with BMC and your research papers will be:

- available free of charge to the entire biomedical community

- peer reviewed and published immediately upon acceptance

- cited in PubMed and archived on PubMed Central

- yours - you keep the copyright

Submit your manuscript here:

http://www.biomedcentral.com/manuscript/
BioMedcentral.com editorial@biomedcentral.com 